\title{
Erratum: Cloning, overexpression and biocatalytic exploration of a novel Baeyer-Villiger monooxygenase from Aspergillus fumigatus Af 293
}

\author{
Maria Laura Mascotti ${ }^{1}$, Maximiliano Juri Ayub ${ }^{2}$, Hanna Dudek ${ }^{3}$, Marcela Kurina Sanz ${ }^{1 *}$ and Marco W Fraaije ${ }^{3^{*}}$
}

\section{Correction}

In the legend of Figure 2 of the original version of this article (Mascotti et al. 2013) the caption read as follows:

Figure 2. Spectral characterization of $\mathrm{BVMO}_{\mathrm{Afl}}$. Visible spectra of native $\mathrm{BVMO}_{\mathrm{Af1}}$ (solid line) and $\mathrm{BVMO}_{\mathrm{Af1}}$ after unfolding by $1 \%$ SDS and incubation at $80^{\circ} \mathrm{C}$ (dotted line). Spectral changes observed upon reduction of $\mathrm{BVMO}_{\mathrm{Af} 1}$ by excess of NADPH (dashed line).

The listing of '(solid line)' and '(dotted line)' are incorrectly placed in the text and in fact should be located in reverse. The caption should correctly read as follows:

Figure 2. Spectral characterization of $\mathrm{BVMO}_{\mathrm{Afl}}$. Visible spectra of native $\mathrm{BVMO}_{\mathrm{Afl}}$ (dotted line) and $\mathrm{BVMO}_{\mathrm{Afl}}$ after unfolding by $1 \%$ SDS and incubation at $80^{\circ} \mathrm{C}$ (solid line). Spectral changes observed upon reduction of $\mathrm{BVMO}_{\mathrm{Af1}}$ by excess of NADPH (dashed line).

\footnotetext{
Author details

'INTEQUI-CONICET, Facultad de Química Bioquímica y Farmacia, Universidad Nacional de San Luis, CP 5700 San Luis, Argentina. ${ }^{2}$ IMIBIO-CONICET, Facultad de Química Bioquímica y Farmacia, Universidad Nacional de San Luis, CP 5700 San Luis, Argentina. 'aboratory of Biochemistry, Groningen Biomolecular Sciences and Biotechnology Institute, University of Groningen, Nijenborgh 4, 9747 AG, Groningen, The Netherlands.
}

Received: 28 July 2014 Accepted: 28 July 2014

Published online: 20 September 2014

\section{Reference}

Mascotti ML, Maximiliiano JA, Dudek H, Sanz MK, Fraaije MW (2013) Cloning, overexpression and biocatalytic exploration of a novel Baeyer-Villiger monooxygenase from Aspergillus fumigatus Af293. AMB Express 3:33

doi:10.1186/s13568-014-0062-7

Cite this article as: Mascotti et al: Erratum: Cloning, overexpression and biocatalytic exploration of a novel Baeyer-Villiger monooxygenase from Aspergillus fumigatus Af293. AMB Express 2014 4:62.

\footnotetext{
* Correspondence: marcelakurina@gmail.com; m.w.fraaije@rug.nl 'INTEQUI-CONICET, Facultad de Química Bioquímica y Farmacia, Universidad Nacional de San Luis, CP 5700 San Luis, Argentina

3Laboratory of Biochemistry, Groningen Biomolecular Sciences and Biotechnology Institute, University of Groningen, Nijenborgh 4, 9747 AG, Groningen, The Netherlands

Full list of author information is available at the end of the article
}

Submit your manuscript to a SpringerOpen ${ }^{\odot}$ journal and benefit from:

- Convenient online submission

- Rigorous peer review

- Immediate publication on acceptance

- Open access: articles freely available online

- High visibility within the field

- Retaining the copyright to your article

Submit your next manuscript at springeropen.com 